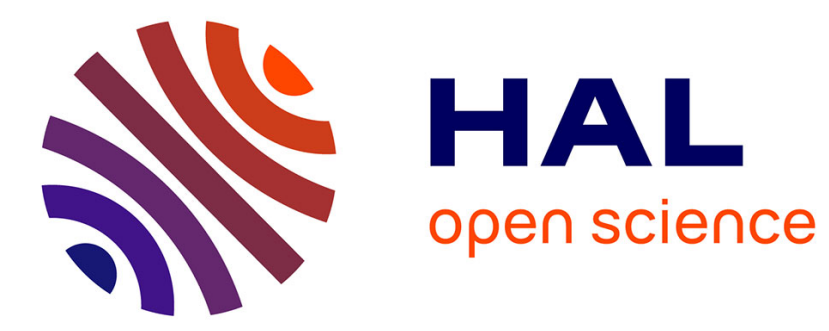

\title{
The role of convection in the transient hot wire method
}

\author{
J. Pantaloni, E. Guyon, M. G. Velarde, R. Bailleux, G. Finiels
}

\section{To cite this version:}

J. Pantaloni, E. Guyon, M. G. Velarde, R. Bailleux, G. Finiels. The role of convection in the transient hot wire method. Revue de Physique Appliquée, 1977, 12 (12), pp.1849-1854.

10.1051/rphysap:0197700120120184900 . jpa-00244412

\section{HAL Id: jpa-00244412 \\ https://hal.science/jpa-00244412}

Submitted on 1 Jan 1977

HAL is a multi-disciplinary open access archive for the deposit and dissemination of scientific research documents, whether they are published or not. The documents may come from teaching and research institutions in France or abroad, or from public or private research centers.
L'archive ouverte pluridisciplinaire HAL, est destinée au dépôt et à la diffusion de documents scientifiques de niveau recherche, publiés ou non, émanant des établissements d'enseignement et de recherche français ou étrangers, des laboratoires publics ou privés. 


\title{
THE ROLE OF CONVECTION IN THE TRANSIENT HOT WIRE METHOD
}

\author{
J. PANTALONI, E. GUYON $\left({ }^{*}\right)$, M. G. VELARDE $\left({ }^{* *}\right)$, R. BAILlEUX and G. FINIELS
}

Laboratoire de Dynamique et Thermophysique des Fluides, (CNRS n ${ }^{\circ}$ 72),

Université de Provence, Centre de St Jérôme 13397 Marseille Cedex 4, France.

(Reçu le 19 août 1976, révisé le 11 juillet 1977, accepté le 7 septembre 1977)

\begin{abstract}
Résumé. - Nous étudions expérimentalement la transition entre deux régimes de transfert de chaleur dans un liquide autour d'un fil vertical dans lequel on dissipe une puissance électrique constante $q$ à partir de l'instant initial $t=0$. Dans un premier régime, le transfert de chaleur est purement diffusif dans la direction horizontale. Le second régime apparaît à un temps caractéristique $t_{\mathrm{c}}$; il correspond à l'apparition d'une composante verticale du gradient thermique. Ce gradient vertical joue un rôle destabilisant sur la couche limite thermique conductive qui se développait lors du $1^{\text {er }}$ régime.

L'étude de cette transition montre que $t_{\mathrm{c}}$ peut être défini par un nombre de Rayleigh ; nous en déduisons une relation entre le temps critique $t_{\mathrm{c}}$, la puissance $q$ et les caractéristiques du fluide.

Abstract. - We study experimentally the transition between two heat transfer regimes in a liquid around a long vertical wire heated by a constant electric power $q$ from an initial time $t=0$. In the first regime (short times) the heat transfer along the horizontal is purely diffusive. The second regime appears after a characteristic time $t_{\mathrm{c}}$ and can be related to a vertical component of the thermal gradient. This vertical gradient plays a destabilizing effect on the conductive boundary layer which develops during the first regime.

The study of this transition indicates that $t_{\mathrm{c}}$ can be defined by means of a Rayleigh number. A relation between the time $t_{\mathrm{c}}$, the power $q$ and the properties of the fluid is given here.
\end{abstract}

1. Introduction. - The transient hot wire technique has been widely used for the determination of the heat diffusivity of electrically insulating materials, mainly because of the relatively simple and rapid (10 s) measurements involved as compared with the stationary methods which requires long s'abilizing times (up to 10 hours; see Bloom et al. [1]).

In fluids rapid measurements are rcquired in order to be able to neglect the effects of convective currents. The characteristic time of measurement must be greater than the response time of the apparatus. This may by a serious limitation of the technique. The present work aims at a clarification of the convective effects in the hot wire method.

Let us recall the principle of the method. A platinum wire of small radius $a$ and of resistance $R$ is placed along the axis of a large vertical cylindrical container filled with the fluid. A current $I$ is applied to the wire at time $t=0$. The temperature increase at the surface of the wire $\theta(a, t)$ is deduced from the variation in time of the resistance $\Delta R(t)$ of the wire. We have

$$
\Delta R(t)=\beta R_{0} \theta(a, t)
$$

(*) Also : Laboratoire de Physique des solides, Université Paris XI 91405 Orsay, France.

(**) Permanent adress : Departamento de fisica - C-3 Universidad Autonoma de Madrid. Cantoblanco Madrid, Spain. in which $R_{0}$ is the initial resistance, $\beta$ the thermal coefficient of resistivity. In a motionless fluid the heat transfer is purely diffusive. It is given by a solution of the Fourier equation in cylindrical geometry

$$
\partial \theta / \partial t=\chi\left(\partial^{2} \theta / \partial r^{2}+(1 / r) \partial \theta / \partial r\right)
$$

where, $r$ is the radial variable.

At $t=0$, a constant power $q$ is dissipated per unit lenght of the wire. If we assume an infinite fluid medium, the temperature increment at a distance $r$ from the wire axis is given by [3]

$$
\theta(r, t)=-[q /(4 \pi \lambda)] E_{\mathrm{i}}\left(-r^{2} /(4 \chi t)\right)
$$

where $E_{\mathrm{i}}$ is the exponential integral, $\lambda$ the heat conductivity of the fluid and $\chi$ its heat diffusivity $(\chi=\lambda / \rho c$ where $\rho$ is the specific mass, $c$ the specific heat of the liquid).

In the presence of a horizontal temperature gradient, hydrostatic equilibrium is not possible and convective motions exist from the initial time. However, the experiments indicate that the solution of the Fourier equation describes the experimental data very satisfactorily as long as $t$ remains smaller than some characteristic time $t_{\mathrm{c}}$.

Above $t_{\mathrm{c}}$ systematic deviations from equation (2) are observed.

Incorporating convective phenomena $\mathbf{v}(r, z)$ in the 
heat equation we have (ignoring the negligible viscous terms)

$$
[\partial / \partial t+(\mathbf{v} . \nabla)] \theta=\chi\left[\partial^{2} \theta / \partial r^{2}+(1 / r) \partial \theta / \partial r\right] .
$$

The deviation from (2) above $t_{\mathrm{c}}$ can be related to a transition between the two following regimes :

$$
\begin{aligned}
& t<t_{\mathrm{c}}:(\mathrm{v} \nabla) \theta=0 \\
& t>t_{\mathrm{c}}:(\mathrm{v} \nabla) \theta \neq 0
\end{aligned}
$$

Such a transition can be due either :

A) to a delay in the establishment of the convective regime ;

B) to the development of a radial component of $\mathbf{v}$;

C) to the existence of a vertical component of $\nabla \theta$.

We will study the critical time for different liquids using the evaluation of the variation $\theta(a, t)$. Visualization experiments will test the possibilities A) and B) and temperature measurements within the fluid will test the third possibility C). We are able to propose an empirical relation between $t_{\mathrm{c}}, q$ and the properties of the fluid.

2. Experimental study. -2.1 Principle. - The variation of the resistance

$$
\Delta R(t)=\Delta V(t) / I
$$

is obtained from the variation $\Delta V(t)$ of the voltage drop along two intermediate electrodes $B$ and $C$ (Fig. 1), using a constant current supply across AD.

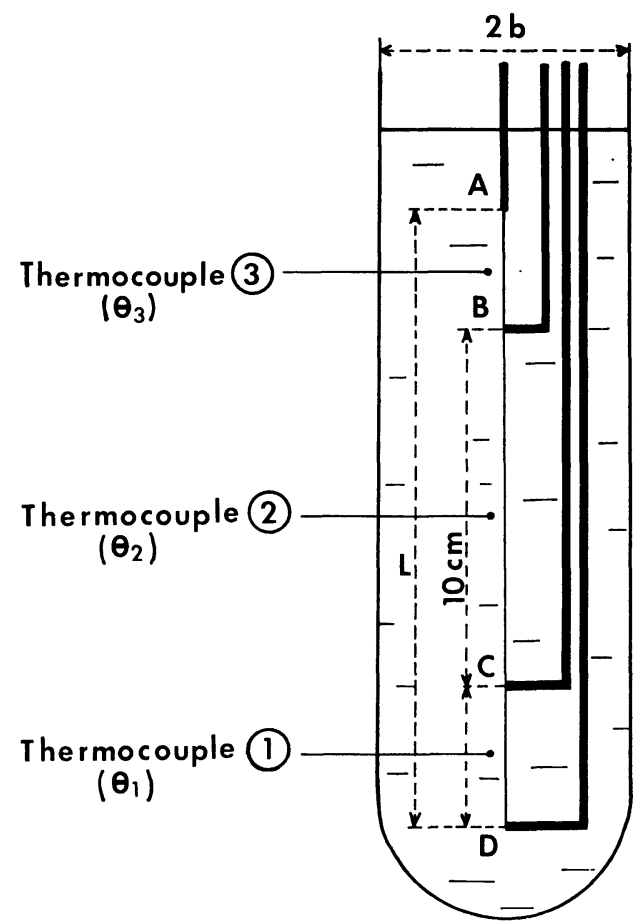

Fig. 1. - Schematic representation of the cell : the platinum wire is stretched between $A$ and $D$, they are the current electrodes, $\mathrm{B}$ and $\mathrm{C}$ are the voltage electrodes. The radius of the platinum wire, $a=2.5 \times 10^{-3} \mathrm{~cm}$, is much smaller than its length, $L \geqslant 14 \mathrm{~cm}$, and the cell radius $b \geqslant 1 \mathrm{~cm}$. All conductors are of platinum.
We can estimate the temperature variations of the wire within $\pm 10^{-3}$ degree.

The time associated with the heat diffusivity across the wire, $\chi_{\mathrm{w}}$, is very small $\left(a^{2} / 4 \chi_{\mathrm{w}} \sim 10^{-5} \mathrm{~s}\right)$ compared to the corresponding value for the liquid

$$
\left(a^{2} / 4 \chi \sim 10^{-3} \mathrm{~s}\right) ;
$$

we will assume that, over the time scale of our experiments $(t \sim 1 \mathrm{~s})$, the temperature is uniform across the wire. Mc Laughlin and Pittman [4] have shown that, under these conditions, one can assume that the temperature of the wire is also equal to that of the liquid at the interface with negligible error.

2.2 EXPERIMENTAL RESULTS. - Figure 2 gives a sequence of results obtained using ethyl alcohol at $0{ }^{\circ} \mathrm{C}$. Times are normalized to $t^{\prime}$, the response time of the apparatus. The set of curves obtained for different powers $q$ indicate a linear variation of the voltage drop $V(t)-V\left(t^{\prime}\right)$ for short times and a systematic deviation from linearity for larger values of $t / t^{\prime}$.

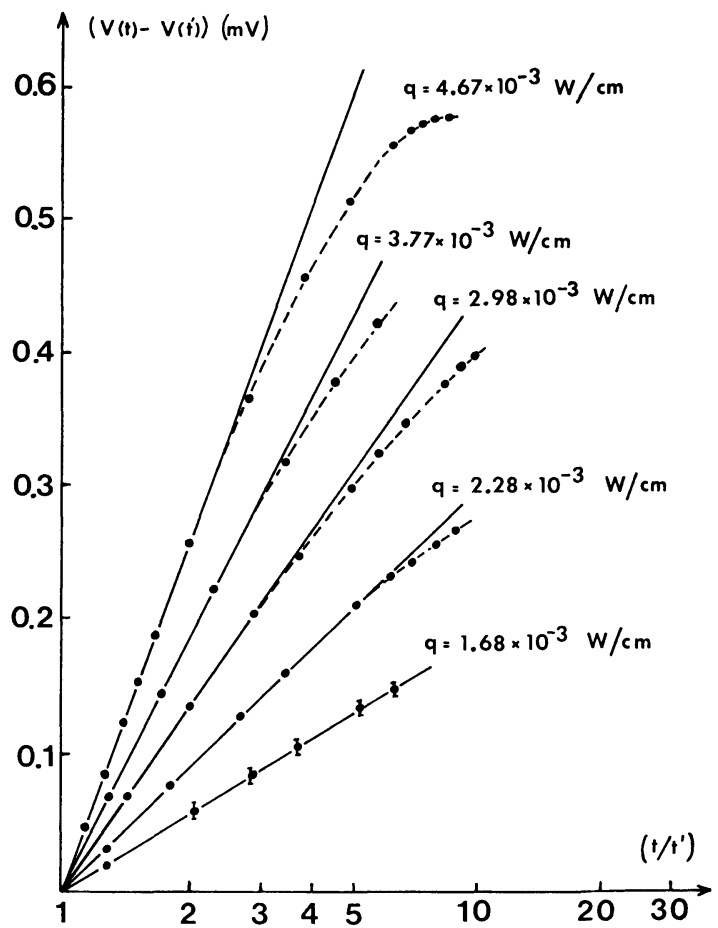

Fig. 2. - Heating curves as a function of the reduced time $t / t^{\prime}$, where $t^{\prime}$ is the response time of the apparatus. The linear slope $p$ (proportional to the power $q$ ) is a measure of the thermal conductivity $\lambda$. Departure from linearity indicates the onset of a different convective regime.

2.3 Stage (i) $\left(t<t_{\mathrm{c}}\right)$. - The time dependence of the temperature of the wire can be estimated by applying equation (2) to the liquid in contact with the wire $(r=a)$

$$
\theta(a, t)=-[q /(4 \pi \lambda)] E_{\mathrm{i}}\left[-a^{2} /(4 \chi t)\right] .
$$

This has been justified for conditions corresponding to our experiments by Mc Laughlin and Pittman [4]. 
Expanding this relation for large times

$$
\left(a^{2} / 4 \chi \ll t<t_{\mathrm{c}}\right)
$$

yields

$$
\theta(a, t)=[q /(4 \pi \lambda)] \log \left[4 \chi t /\left(\gamma^{\prime} a^{2}\right)\right]
$$

$\gamma^{\prime}=1.78106 \ldots$

Using relations (3) and (1), we get

$$
V(t)-V\left(t^{\prime}\right)=\left[\beta R_{0} q I /(4 \pi \lambda)\right] \log \left(t / t^{\prime}\right) .
$$

The linear slope of the variation displayed on figure 2 leads to a determination of the heat conductivity $\lambda$. We can also check that the slope is a linear function of $q$ (Fig. 3).

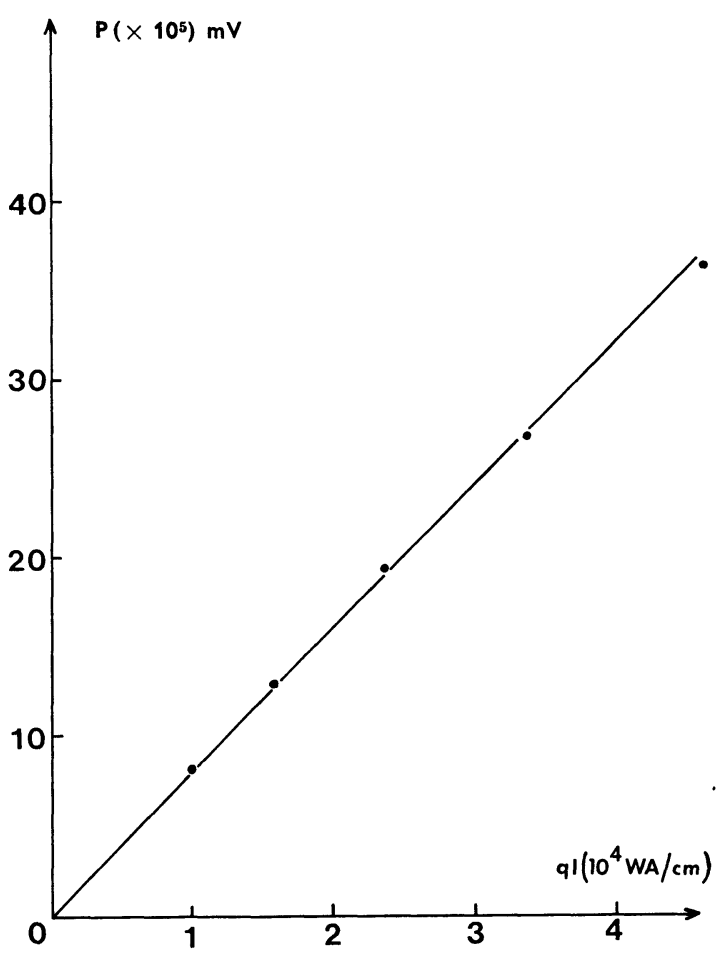

Fig. 3. - The slope $p$ for the first convective state $\left(t<t_{\mathrm{c}}\right)$ varies linearly with $q I$ (see equation (6)).

The results obtained for different fluids using this method are given together with tabulated values

$\begin{array}{lcc}\lambda\left(\times 10^{4}\right) & \begin{array}{c}\mathrm{cal} /(\mathrm{cm} . \mathrm{s} . \mathrm{K}) \\ \text { other data }\end{array} \\ & - & - \\ \text { Ethyl alcohol } 0{ }^{\circ} \mathrm{C} & 4.14 & 4.05[5] ; 4.41[6] \\ \text { Toluene } 0{ }^{\circ} \mathrm{C} & 3.74 & 3.4[7] ; 3.93[6] \\ \text { Silicone oil } 22^{\circ} \mathrm{C} & 3.23 & \sim 3.5[8]\end{array}$

2.4 STAGE (ii) $\left(t>t_{\mathrm{c}}\right)$. - Figure 4 gives in reduced units the variation of $\theta(a, t)$ as a function of $\log t$ for three different liquids. The curves clearly show that beyond a characteristic time $t_{\mathrm{c}}$ that depends on the liquid and on $q$, (5) is no longer satisfied. The time $t_{\mathrm{c}}$ increases with the Prandtl number of the fluid and decreases with $q$ for a given liquid.

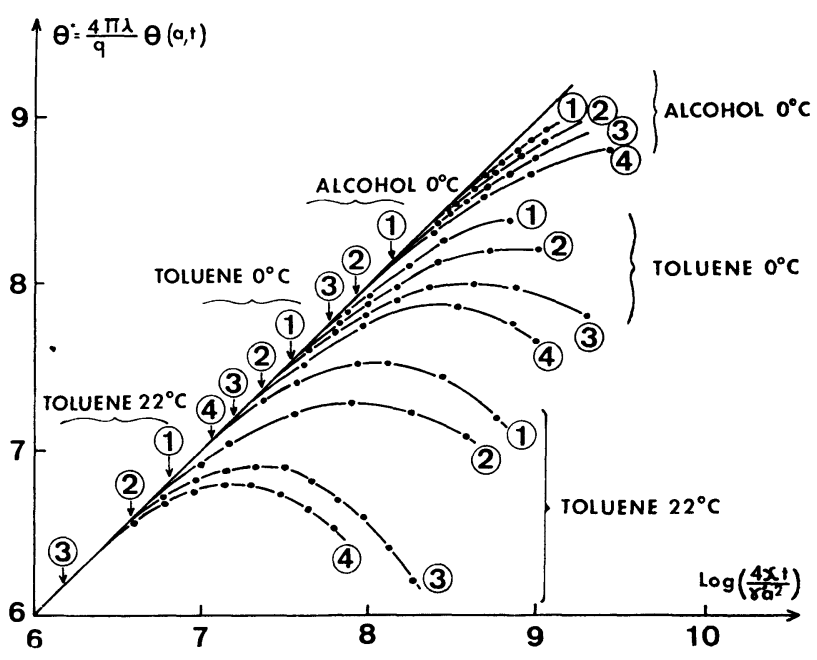

FIG. 4. - The results of figure 1 expressed in dimensionless form are given for alcohol at $0{ }^{\circ} \mathrm{C}$, toluene at $0{ }^{\circ} \mathrm{C}$ and toluene at $22{ }^{\circ} \mathrm{C}$. For toluene at $22^{\circ} \mathrm{C}$, we give data points for two different cells $(b=I$ and $2.25 \mathrm{~cm})$. We see that wall effects are not appreciable for the values of $t$ in this figure (see however Fig. 6). Alcohol $\left(0^{\circ} \mathrm{C}\right)$ : curve $1: q=1.67 \times 10^{-3} \mathrm{~W} / \mathrm{cm}$; curve 2 : $q=2.40 \times 10^{-3} \mathrm{~W} / \mathrm{cm} ;$ curve $3: q=3.14 \times 10^{-3} \mathrm{~W} / \mathrm{cm}$; curve $4: q=4.92 \times 10^{-3} \mathrm{~W} / \mathrm{cm}$. Toluene $\left(0^{\circ} \mathrm{C}\right):$ curve $1:$ $q=1.78 \times 10^{-3} \mathrm{~W} / \mathrm{cm} ;$ curve $2: q=2.42 \times 10^{-3} \mathrm{~W} / \mathrm{cm}$; curve 3: $q=3.16 \times 10^{-3} \mathrm{~W} / \mathrm{cm}$; curve $4: q=4.00 \times$ $10^{-3} \mathrm{~W} / \mathrm{cm}$. Toluene $\left(22^{\circ} \mathrm{C}\right):$ curve $1: q=3.34 \times 10^{-3} \mathrm{~W} / \mathrm{cm}$; curve $2: q=5.24 \times 10^{-3} \mathrm{~W} / \mathrm{cm} ;$ curve $3: q=1.03 \times$ $10^{-2} \mathrm{~W} / \mathrm{cm}$; curve $4: q=1.36 \times 10^{-2} \mathrm{~W} / \mathrm{cm}$. The arrows indicate the departure from linearity deduced from equation (11).

We investigate the effect of the geometry by varying - the distance $L$ between the intermediate electrodes $B$ and $C$;

- the distance $C D$ between those at the bottom;

- the geometry of the container.

On figure 5 we have plotted directly the departure from linearity for a given liquid and for different lengths of wire. The characteristic time hardly depends on $L$.

According to Mc Laughlin and Pittman [4] a departure from linearity in the $\Delta V(\log t)$ curve (Fig. 2) is expected when a perturbation initiated at the bottom

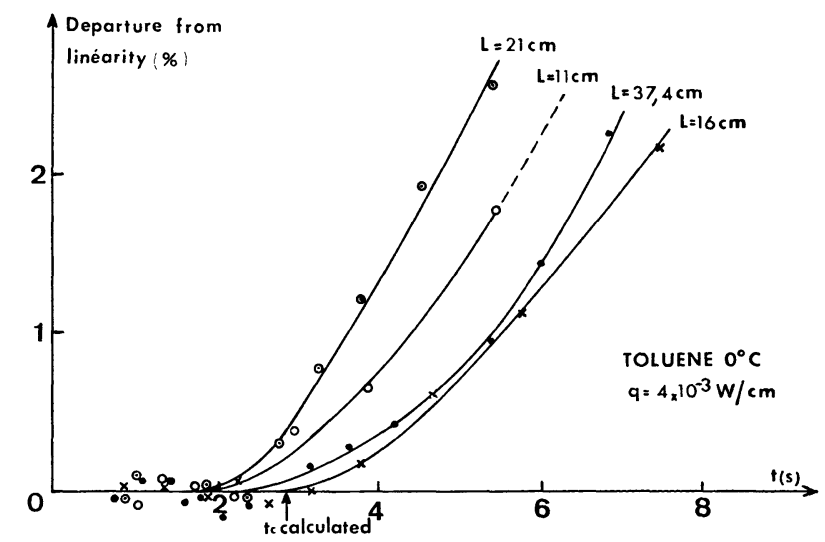

Fig. 5. - Departure from linearity for a given liquid and for different lengths of wire. The characteristic time hardly depends on $L$ and is in good agreement with calculated value equation (11). 
(D) of the wire when the current is applied, reaches electrode $C$. In order to test this effect we have varied $C D$ from 0 to $20 \mathrm{~cm}$. We have found no appreciable dependence of $t_{\mathrm{c}}$ with $C D$. Similarly no dependence has been found on the total height of the liquid.

In addition the short time behaviour $\left(t<t_{\mathrm{c}}\right)$ is found to be independent of the geometry of the cell, which is to be expected. Boundary effects are appreciable however for times much larger than $t_{\mathrm{c}}$ (see Fig:6).

In conclusion, we find that the transition between (i) and (ii) is essentially independent of geometry and depends only on the heat dissipated but the wire.

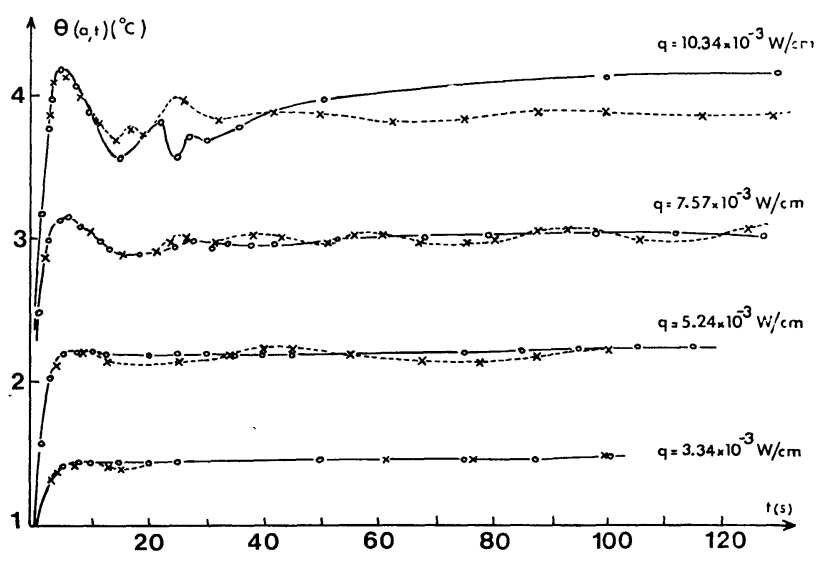

Fig. 6. $-\theta(a, t)=f(t)$ for toluene at $22^{\circ} \mathrm{C}$ using two cells (0: small cell $(b=1 \mathrm{~cm}), x$ : wide cell $(b=2.25 \mathrm{~cm}))$. For large values of $t$, oscillations appear; the amplitude of these oscillations depend on the geometry of the cell.

3. Study of the fluid motion. - Goldstein and Briggs [9] have studied numerical solutions of the equations of fluid motion during the first state (i). These authors assume a radially diffusive heat transfer, $\mathbf{v}$ having no radial component; they show that the vertical component exists already for $t>0$ and is maximum at a distance $r$ smaller than the tickness ( $\sim \sqrt{\chi t}$ ) of the thermal boundary layer. This result shows clearly that a motion state for the fluid is consistent with a radially diffusive heat transfer.

However Gebhart [10] states that in the case of a vertical plane the convective motion can be delayed. Since these two results seem contradictory, we have conducted direct visualization tests.

\subsection{DiReCt Visualization OF THE MOtION AT THE} TOP SURFACE. - In a finite container, mass conservation demands that the existence of a vertical velocity be accompanied by a radial motion along the bottom and top boundaries. We shall describe the motion observed with silicone oil for which the characteristic time is comfortably large to allow detailed measurements.

The oil is doped with fine $A l$ flakes. The flakes move with the fluid and, due to their elongated shape, they align with the flow. An 18 frames/s movie film of the surface provides pictures of the type of those of figure 7 .

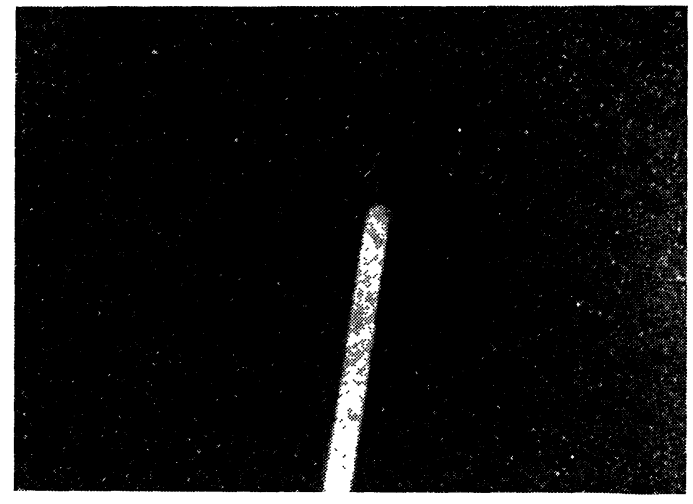

FIG. $7 a$

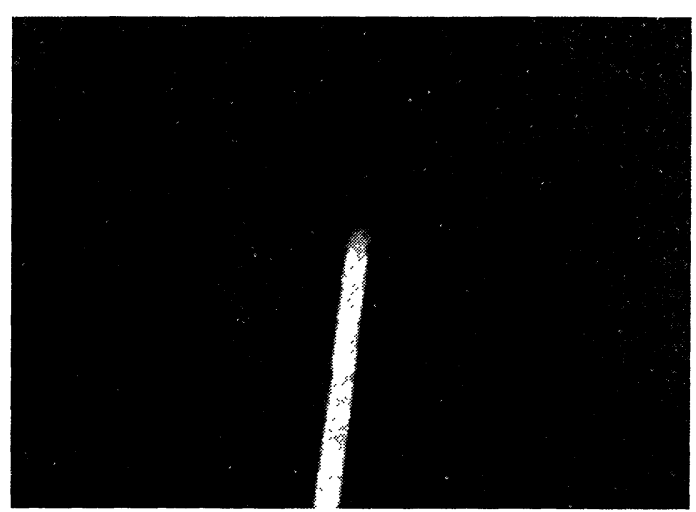

FIG. $7 b$

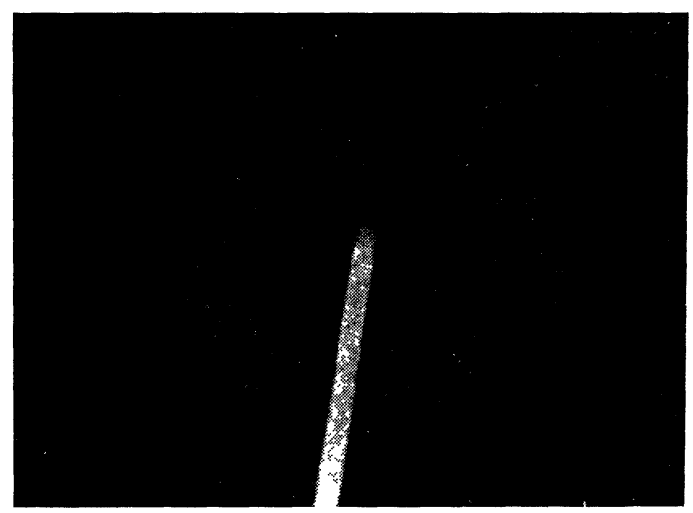

Fig. $7 c$

Fig. 7. $-a)$ film of the free upper surface at time $t=0$; $b$ ) film of the free upper surface at time $\left.t<t_{\mathrm{c}} ; c\right)$ film of the free upper surface at time $t>t_{\mathrm{c}}$. The motion exists for $t<t_{\mathrm{c}}$, i. e. when the heat transfer is purely diffusive in the horizontal direction.

In the central part the dark region comes from the effect of the large gradient which aligns the particles vertically causing very little reflection of the incident light. A bright circular spot of diameter $d$ is obtained. A frame by frame analysis is used to characterize the increase of the diameter $d$ with time. The results are given in figure 8 .

We see that the motion exists already for $t<t_{\mathrm{c}}$. This rules out the first possibility (A) of section 1 as 


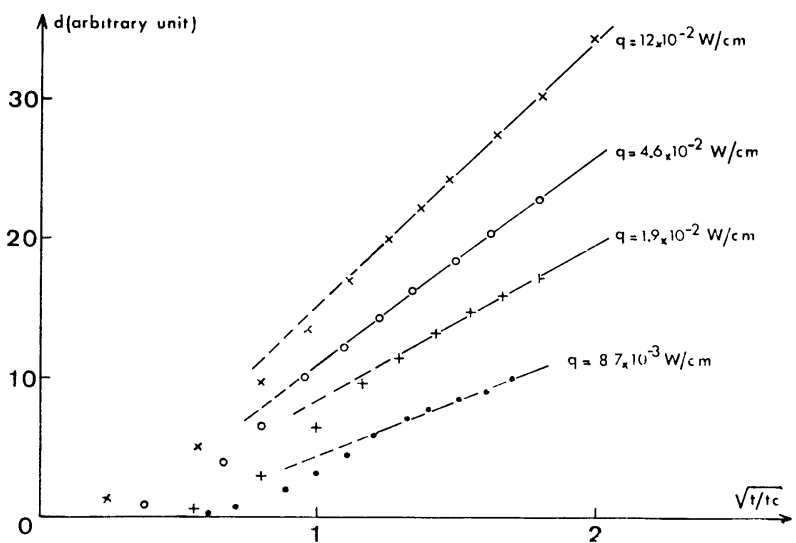

Fig. 8. - We have plotted the spot diameter (see Fig. 7) as a function of reduced time $\sqrt{t / t_{\mathrm{c}}}$. We see clearly a change of around $t / t_{\mathrm{c}} \sim 1$.

the origin of a transition. We also see a change of regime around $t / t_{\mathrm{c}}=1$. The linear variation in $\sqrt{t}$ (for $t>t_{\mathrm{c}}$ ) is an indication of a steady regime with a constant flow rate directed radially outwards from the wire at the upper surface.

3.2 DePendenCe Along THE LENGTH OF THE WiRe. - A Schlieren-type visualization of the flow taken horizontally across the cell, shows that the velocity is always vertical except near the edge of the cell (in order to comply with the mass conservation). We have not been able to observe any transition from this unicellular motion to a multicellular regime such as appears for a vertical plane layer (Elder [11]). Here the boundary layer regime along the wire is clearly dominant. When the horizontal gradient is increased, a turbulent regime is created all along the length of the wire. This motion is related to the temperature oscillation which appear at long enough time (Fig. 6).

These results clearly rule out B (section 1) as a cause of the transition at $t=t_{\mathrm{c}}$ and are fairly consistant with numerical results of Goldstein and Briggs [9] which indicate that the diffusive thermal boundary layer exists in state (i) in the presence of a vertical motion. We do not observe similar results of those of Elder [11] for plane layer ; this is consistent with the studies of Sparrow and Gregg [12] which show that similarity might be observed only if the boundary layer were small compared to the diameter of the wire, which is not the case here.

4. Temperature distribution around the wire. - We now turn to a test of the third hypothesis $\mathrm{C}$ (Section 1). We have measured directly the vertical temperature gradient in the neighbourhood of the wire. We use three thermocouples located as indicated on figure 1 and we measure the difference $\Delta \theta^{\prime}=\theta_{1}-\theta_{2}$ and $\Delta \theta^{\prime \prime}=\theta_{3}-\theta_{2}$. On figure 9 we see the temporal evolution of these two quantities. As long as $t$ is smaller than a time $t_{\mathrm{t}}$ no gradient can be detected. Past this time and before the stationnary state, we detect a

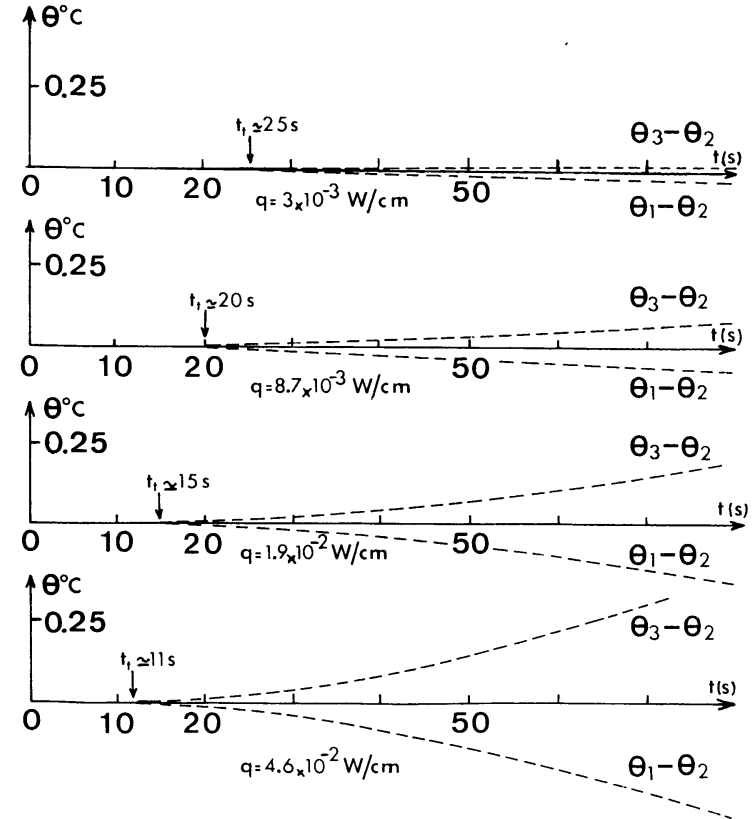

Fig. 9. - Vertical temperature gradient in the neighbourhood of the wire for some values of power $q$. As long as $t$ is smaller than a time $t_{\mathrm{t}}$, no gradient is detected ; past this time we detect a regular and symmetric increase of the vertical temperature regime gradient.

regular and symmetric increase of $\Delta \theta^{\prime}$ and $\Delta \theta^{\prime \prime}$. The gradient is thus symmetrical around point 2. Morever by displacing the thermocouples 1 and 3 we have checked that the gradient is uniform along the vertical.

Thus the transition beetween states (i) and (ii) can be satisfactorily explained by the effect of this gradient. The convective contribution is due of the vertical velocity on the vertical component of the temperature gradient. Note that the (adverse) sign of this component is such that it tends to limitate the amplitude of the convective velocity.

5. The characteristic times. - Two apparent time scales can be associated with the primary flow. On one hand, we have introduced (see section 2) $t_{\mathrm{c}}$ by detecting the departure from linearity in the $(\Delta V, \log t)$ diagram (Fig. 2) and associated with the mean temperature along the wire. On the other hand, a second scale, $t_{t}$, can be associated with first appearance of a vertical component of the thermal gradient and this occurs before $t_{\mathrm{c}}$ as would be expected. For $t_{\mathrm{t}}<t<t_{\mathrm{c}}$, the mean value $\theta(a, t)$ is not affected by the vertical component of $\Delta \theta$ and the transient hot wire method can still be used to measure the thermal conductivity in fluids. Thus the important parameter of this method is clearly $t_{\mathrm{c}}$. This characteristic parameter of the problem can be defined in terms of an adhoc Rayleigh number that expresses in dimensionless form the horizontal gradient which drives the basic convective motion along the wire

$$
R_{\mathrm{a}}(t)=[\alpha g /(v \chi)] r_{\mathrm{i}}^{3} \theta(a, t)
$$


$\alpha$ is the thermal expansion coefficient of the fluid, $g$ the acceleration of gravity, $v$ the kinematic velocity. The characteristic length $r_{\mathrm{i}}$ is estimated from the value of the thermal boundary layer tickness

$$
r_{\mathrm{i}}=k \sqrt{\chi t}
$$

where $k$ is a numerical factor.

Using equation 5 we get

$$
R_{\mathrm{a}}(t)=\left[k^{3} \alpha g \chi^{1 / 2} v\right][q / 4 \pi \lambda] t^{3 / 2} \log \left[4 \chi t /\left(\gamma^{\prime} a^{2}\right)\right] .
$$

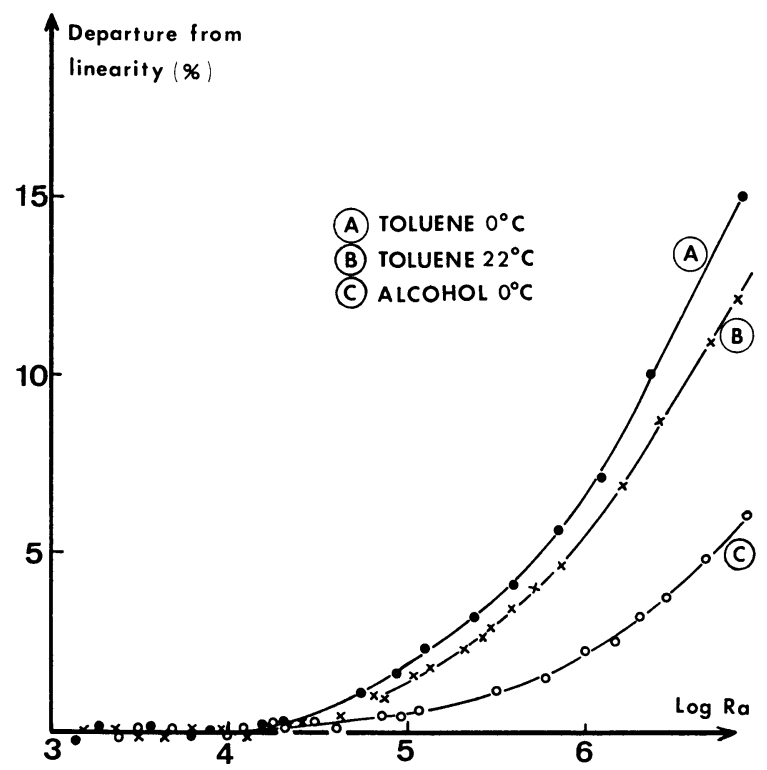

Fig. 10. - Departure from linearity plotted as a function of an ad hoc Rayleigh number. These results are consistent with an unique value of the Rayleigh number for the characteristic time. This result yields an implicit relation between $t_{\mathrm{c}}, q$ and fluid see equation properties (11).

The curves of figure 10 give the deviation from the linear behaviour (similar to Fig. 5) for three different liquids in terms of this Rayleigh number. The different results presented are consistent with a unique value of the Rayleigh number for the characteristic time $t_{\mathrm{c}}$ :

$$
R_{\mathrm{a}}\left(t_{\mathrm{c}}\right) \sim 30 k^{3} .
$$

Relations (9) and (10) yield an implicit relation between $t_{\mathrm{c}}, q$ and the fluid properties

$$
t_{\mathrm{c}}^{3 / 2} \log \left(4 \chi t_{\mathrm{c}} / \gamma^{\prime} a^{2}\right)=380 \operatorname{Pr} \chi^{1 / 2} \lambda /(\alpha g q)
$$

where $\operatorname{Pr}$ is the Prandtl number $(=v / \chi)$.

The values of $t_{\mathrm{c}}$ deduced from this expression are indicated by arrows on figure 4 . We see that they agree well with the experimental departure from linearity.

4. Conclusion. - By analogy with the problem of a horizontal fluid layer heated from below it had been postulated that, below a critical Rayleigh number, there existed a state with no hydrodynamic velocity in the vertical hot wire problem $[13,14,15]$. This result is inconsistent with our experimental results and can not be a solution of the hydrodynamic problem.

In the initial stage (i), the vertical motion develops within the thermal boundary layer. We have also shown that only a single cell forms in this cylindrical geometry. The transition to state (ii) has been shown to be related to a vertical component of the thermal gradient which gives rise to convective heat transfert and leads to a destabilization of the boundary layer. The direction of the gradient is such that it limits the amplitude of the velocity. This saturation effect is also deduced qualitatively from the change of behavior in the visualization experiments from the top surface.

An adhoc Rayleigh number based on the value of the horizontal temperature gradient has been introduced. Relation (11) can be used to get an a priori estimate of the maximum available time $\sim t_{c}$ for the applicability of the technique for heat diffusivity measurements.

The time $t_{\mathrm{c}}$ should not be considered as an intrinsic critical value and its determination from the hot wire or thermocouples experiment can be a function of the sensitivity of the measurements. However we can, in any case, clearly differentiate the asymptotic regimes (i) and (ii) as also found from the visualization experiments.

Acknowledgments. - We have had a stimulating discussion with Y. Pomeau on this problem. We also acknowledge a critical reading of the manuscript by M. Woolf.

\section{References}

[1] BLoom et al. - Aust. J. Chem. 18 (1965) 1171-76.

[2] Anderson, P. and Bäckströм, G., Rev. Sci. Instrum. 47 (1976) 205-209.

[3] Carslaw, B. S. and Jaeger, J. C., Conduction of heat in Solids (Oxford) 1959 p. 261.

[4] Mc Laughin, E. and Pittman, J. F. T., Phil. Trans. Roy. Soc. London A 270 (1971) 557.

[5] Handbook of chemistry and physics (56th Edition) 1975-1976 ; - Timmermans, J., Physico-chemical constants of pure organic compounds (Elsevier Publ. Comp. Inc.) 1950 p. 99-150-253-306.

[6] FABRY, C., Propagation de la chaleur, (Armand Colin Editeur, Paris) 1942.
[7] Powel, R. W., Ho, C. Y. and Liley, P. E., Report NSRDSNBS8 (see reference 5).

[8] Notice technique «Rhodorsil Huiles», Rhone Poulenc (1976).

[9] Goldstein, R. J. and Briggs, D. G., J. Heat Transf. (A. S. M. E.) 86 (1964) 490

[10] Gebhart, B., Heat Transfer; (Tata Mc Graw-Hill Publishing Company, $2^{\mathrm{e}}$ éd.) 1971 p. 359.

[11] EldER, J. W., J. Fluid Mech. 24 (1966) 823.

[12] Sparrow, E. M. et GregG, J. L., Trans. A. S. M. E., (1956) 1823.

[13] VAN DeR Held, E. F. M. and VAn DRunen, F. G., Physica 15 (1949) 865.

[14] White, L. R. and Davis, H. T., J. Chem. Phys. 47 (1967) 12.

[15] Turnbull, A. G., Austr. J. Appl. Sci. 12 (1961) 324. 